\title{
Assessing Impacting Factors of Dog Owners' Adoption of Dog Vaccination Against Rabies: A Cross-sectional Survey in Rural Areas - Guangxi Zhuang Autonomous Region, China, 2021
}

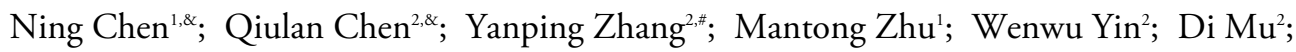 \\ Yu Li'; Yingjie Chen'; Yidan Deng; ${ }^{3}$ Xianyan Tang ${ }^{1, *}$
}

\section{Summary}

What is already known about this topic?

Rabies is fatal while preventable. More than $99 \%$ of human rabies cases were caused by dog bites worldwide. Mass dog vaccination could interrupt dogmediated rabies if achieving and maintaining a minimum coverage rate of $70 \%$.

\section{What does this report contribute?}

The results of this study show that roughly $23.7 \%$ of households owned dogs in Guangxi Zhuang Autonomous Region, China but only about $19.1 \%$ of these households reported having their dogs vaccinated. Possible positive factors were injury history of dog bites, awareness of the necessity, and policy help for the costs of dog vaccination, but negative factors were negative attitude and inaccessibility.

What are the implications for public health practices?

Much more effort should be made to improve dog vaccination coverage in rural areas in Guangxi Zhuang Autonomous Region, China. Well-designed free mass vaccination campaigns with more accessibility and awareness campaigns are important to improve coverage.

Although rabies is an almost $100 \%$ fatal zoonotic disease once symptoms appear, rabies can be prevented by vaccines. More than $99 \%$ of human rabies cases were caused by $\operatorname{dog}$ bites worldwide (1). However, achieving and maintaining a minimum dog vaccination coverage of $70 \%$ has been proven to interrupt dog-mediated rabies (1). Southern China is a rabies-endemic region, with most human rabies cases occurring in rural areas of this region (2). In 2015, the World Health Organization, the World Organisation for Animal Health, and the Food and Agriculture Organization of the United Nations (FAO) in collaboration with Global Alliance for Rabies Control proposed eliminating dog-mediated rabies globally by 2030 ("zero by 2030"). Although the vaccination coverage among registered dogs is required to meet 90\% by the National Animal Rabies Prevention and Control Plan (3), current low vaccination coverage in dogs was the main obstacle for China to eliminate dogtransmitted rabies (4). Therefore, it is important to know the impacting factors associated with low dog vaccination rates in rural areas to design well-targeted rabies control programs. This study conducted a household survey on evaluating influencing factors of dog vaccination against rabies using a uniform structural questionnaire to interview 533 dog-owning households out of 2,432 households surveyed in 127 villages of Guangxi Zhuang Autonomous Region, a provincial-level administrative division (PLAD) with 24.26 million rural residents in China in 2021, based on a multistage random sampling method. Results indicated that facilitating factors for dog vaccination were injury history of dog bites, awareness of the necessity, and policy help for the costs of dog vaccination, while hindering factors were negative attitudes and inaccessibility to dog vaccinations. It is recommended to scale up free and more accessible mass dog vaccinations, as well as conduct an awareness campaign to improve dog rabies vaccination coverage in rural China.

The study calculated the sample sizes using the formula given by Thrusfield as follows: $N=Z^{2} \mathrm{P}(1-$ $\mathrm{P}) / \mathrm{M}^{2}$. The $Z$ value is 1.96 at the confidence interval (CI) of $95 \%, \mathrm{P}$ is the estimated domestic dog vaccination coverage percentage, set at $50 \%$ in this study, and $\mathrm{M}$ is the standard error set at 0.05 . The minimum required sample size was 384 households, and this research investigated 533 dog-owning households in total. A multistage random sampling method was used to select 2,432 households in rural areas of Guangxi Zhuang Autonomous Region in China for investigation. The household survey was 
conducted from January to March 2021. The interviewer asked the selected households whether their family owns any dogs; if the answer was no, then the interview would end; if the answer was yes, then the questionnaire was continued. The family head or a substitute family member aged above 18 years old was interviewed face-to-face. The information collected for each interviewee included the demographical characteristics such as gender, age, education level, reasons for raising dogs, dog vaccination status, the reasons of failing to vaccinate if that was the case, awareness of rabies, and the local dog rabies vaccination cost policy. $\mathrm{R}$ software (version 4.0.4, University of Auckland, New Zealand) was used to perform chi-squared tests to do univariate analysis and binary logistic regression model to control the confounding factors, with $P<0.05$ was considered statistically significant.

Among the 2,432 households surveyed, 578 households reported owning dogs. The household dogowning rate was $23.7 \%(578 / 2,432)$. Overall, 45 households failed to answer the vaccination status of the dogs and were excluded. Finally, there were 533 dog-owning households that were investigated. Only 102 out of these 533 households reported having their dogs vaccinated against rabies, with a coverage rate of $19.1 \%(102 / 533)$. The main reasons for owning dogs were guarding the house $(84.8 \%)$ and liking dogs (32.9\%). The main reasons of failing to get their dogs vaccinated against rabies included not knowing the dogs needed to be vaccinated against rabies $(51.1 \%)$, thinking the process was too troublesome (44.6\%), and not knowing where to vaccinate $(31.5 \%)$ (Table 1$)$.

Out of the 533 responders from theses 533 households, 257 responders (48.2\%) were male and 276 responders $(51.8 \%)$ were female. The majority of these responders were young adults and middle-aged people with a median age of 46.2 years old [interquartile range (IQR): $35.0-58.0$ years old]. The educational level of the responders was mainly primary school and below (43.5\%), and junior middle school $(33.4 \%)$. The awareness rates of single rabies related knowledge points among respondents ranged from $34.2 \%$ to $70.0 \%$, while $13.9 \%$ of them had history of injury due to dog bites in the past year.

Univariate analyses results showed that age, education level, awareness of rabies, and injury history of dog bites in the past year were related to dog vaccination status (Table 2). Further binary logistic regression found several promoting factors of dog vaccinations (Table 3 ). The dog owners who had an injury history of $\mathrm{dog}$ bites in the past year were more likely to vaccinate dogs $(\mathrm{OR}=2.124,95 \% \mathrm{CI}$ : 1.059-4.205, $P<0.05)$, compared with those without dog-bite history. Awareness of the necessity and cost policy of dog vaccination were also found to influence dog vaccination. Compared with their respective counterparts, the dog owners who knew that dogs should be vaccinated against rabies $(\mathrm{OR}=4.956,95 \%$ CI: 2.387-10.914, $P<0.01)$, the dog owners who knew local free policy of dog vaccines against rabies, $(\mathrm{OR}=3.290$, 95\% CI: $1.285-8.296, P<0.05)$, and the dog owners who knew the price of dog vaccination against rabies $(\mathrm{OR}=1.915$, 95\% CI: 1.048-3.543, $P<0.05)$ were more likely to vaccinate dogs.

\section{DISCUSSION}

This study revealed high dog-owning rates and low dog vaccination coverage in Guangxi Zhuang Autonomous Region, and that injury history of dog bites, awareness of the necessity, and policy help for the costs of dog vaccination were identified as promoting factors for dog owners' adoption of dog vaccination, while negative attitude and inaccessibility to dog vaccination were hindering factors.

People with injury history of dog bites had received rabies knowledge through this unpleasant experience,

TABLE 1. Given reasons why households did not vaccinate their dogs in rural areas of Guangxi Zhuang Autonomous Region, China, $2021\left(n=419^{*}\right)$.

\begin{tabular}{lcc}
\hline \multicolumn{1}{c}{ Reason } & Households in which dogs were not vaccinated \\
\cline { 2 - 3 } & Number & Proportion (\%) \\
\hline Did not know dogs need to be vaccinated against rabies & 214 & 51.1 \\
Did not know where to vaccinate for dogs & 132 & 31.5 \\
Thought that vaccinating dogs was too troublesome & 187 & 44.6 \\
Vaccination too expensive & 46 & 11.0 \\
Other & 30 & 7.2 \\
\hline
\end{tabular}

* Among 533 households, 431 households did not vaccinate their dogs, and 12 households did not give the reasons. 
TABLE 2. Dog-owning households rabies vaccination adoption (owning dog being vaccinated or not) in rural areas of Guangxi Zhuang Autonomous Region, China, 2021.

\begin{tabular}{|c|c|c|c|c|}
\hline Variable & $\begin{array}{c}\text { Households in which dogs } \\
\text { were vaccinated } \\
\mathrm{n}(\%)\end{array}$ & $\begin{array}{c}\text { Households in which dogs } \\
\text { were not vaccinated } \\
\mathrm{n}(\%)\end{array}$ & $\begin{array}{c}\text { Total number of } \\
\text { observed } \\
n(\%) \\
\end{array}$ & $\boldsymbol{P}$ \\
\hline \multicolumn{5}{|l|}{ Gender } \\
\hline Male & $43(42.2)$ & $214(49.7)$ & $257(48.2)$ & 0.173 \\
\hline Female & $59(57.8)$ & $217(50.3)$ & $276(51.8)$ & \\
\hline Total & $102(100.0)$ & $431(100.0)$ & $533(100.0)$ & \\
\hline \multicolumn{5}{|l|}{ Age (years) } \\
\hline $18-30$ & $39(38.2)$ & $76(17.6)$ & $115(21.6)$ & 0.000 \\
\hline $31-50$ & $39(38.2)$ & $164(38.1)$ & $203(38.1)$ & \\
\hline$\geq 51$ & $24(23.5)$ & $191(44.3)$ & $215(40.3)$ & \\
\hline Total & $102(100.0)$ & $431(100.0)$ & $533(100.0)$ & \\
\hline \multicolumn{5}{|l|}{ Level of education } \\
\hline Primary school and below & $24(23.5)$ & $208(48.3)$ & $232(43.5)$ & 0.000 \\
\hline Junior high school & $36(35.3)$ & $142(32.9)$ & $178(33.4)$ & \\
\hline Senior high school and above & $42(41.2)$ & $81(18.8)$ & $123(23.1)$ & \\
\hline Total & $102(100.0)$ & $431(100.0)$ & $533(100.0)$ & \\
\hline \multicolumn{5}{|l|}{ Can rabies be cured? } \\
\hline Yes & $56(54.9)$ & $274(63.6)$ & $330(61.9)$ & 0.105 \\
\hline No & $46(45.1)$ & $157(36.4)$ & $203(38.1)$ & \\
\hline Total & $102(100.0)$ & $431(100.0)$ & $533(100.0)$ & \\
\hline \multicolumn{5}{|c|}{$\begin{array}{l}\text { Do you know that rabies can be prevented by } \\
\text { vaccinations? }\end{array}$} \\
\hline No & $13(12.7)$ & $147(34.1)$ & $160(30.0)$ & 0.000 \\
\hline Yes & $89(87.3)$ & $284(65.9)$ & $373(70.0)$ & \\
\hline Total & $102(100.0)$ & $431(100.0)$ & $533(100.0)$ & \\
\hline \multicolumn{5}{|c|}{$\begin{array}{l}\text { Whether there is an injury history of dog bites } \\
\text { in the past year? }\end{array}$} \\
\hline No & $80(78.4)$ & $379(87.9)$ & $459(86.1)$ & 0.013 \\
\hline Yes & $22(21.6)$ & $52(12.1)$ & $74(13.9)$ & \\
\hline Total & $102(100.0)$ & $431(100.0)$ & $533(100.0)$ & \\
\hline \multicolumn{5}{|c|}{$\begin{array}{l}\text { Do you know that dogs should be vaccinated } \\
\text { against rabies? }\end{array}$} \\
\hline No & $12(12.1)$ & $255(60.4)$ & $267(51.2)$ & 0.000 \\
\hline Yes & $87(87.9)$ & $167(39.6)$ & $254(48.8)$ & \\
\hline Total & $99(100.0)$ & $422(100.0)$ & $521(100.0)$ & \\
\hline \multicolumn{5}{|c|}{$\begin{array}{l}\text { Do you know where to vaccinate dogs against } \\
\text { rabies? }\end{array}$} \\
\hline No & $34(33.7)$ & $315(73.4)$ & $349(65.8)$ & 0.000 \\
\hline Yes & $67(66.3)$ & $114(26.6)$ & $181(34.2)$ & \\
\hline Total & $101(100.0)$ & $429(100.0)$ & $530(100.0)$ & \\
\hline \multicolumn{5}{|l|}{$\begin{array}{l}\text { Do you know the local policy of dog } \\
\text { vaccination against rabies? }\end{array}$} \\
\hline Unknown & $25(24.5)$ & $271(62.9)$ & $296(55.5)$ & 0.000 \\
\hline Charges & $63(61.8)$ & $142(32.9)$ & $205(38.5)$ & \\
\hline Free & $14(13.7)$ & $18(4.2)$ & $32(6.0)$ & \\
\hline Total & $102(100.0)$ & $431(100.0)$ & $533(100.0)$ & \\
\hline
\end{tabular}


TABLE 3. Impact factors of dog owner's adoption of vaccination in rural areas of Guangxi Zhuang Autonomous Region, China, based on a binary logistic regression model.

\begin{tabular}{|c|c|c|c|c|c|c|}
\hline Variable & B & S.E. & Wald & $P$ & $\operatorname{Exp}(B)$ & $95 \% \mathrm{Cl}$ \\
\hline \multicolumn{7}{|l|}{ Gender } \\
\hline Male & Ref. & & & & & \\
\hline Female & 0.303 & 0.259 & 1.366 & 0.242 & 1.354 & $0.816-2.259$ \\
\hline Age (in years) & -0.003 & 0.011 & 0.058 & 0.809 & 0.997 & $0.976-1.019$ \\
\hline \multicolumn{7}{|l|}{ Level of education } \\
\hline Primary school and below & Ref. & & & & & \\
\hline Junior high school & 0.212 & 0.361 & 0.344 & 0.558 & 1.236 & $0.608-2.522$ \\
\hline High school and above & 0.623 & 0.453 & 1.896 & 0.168 & 1.865 & $0.769-4.562$ \\
\hline \multicolumn{7}{|l|}{ Can rabies be cured? } \\
\hline Yes & Ref. & & & & & \\
\hline No & 0.005 & 0.262 & 0.000 & 0.984 & 1.005 & $0.599-1.678$ \\
\hline \multicolumn{7}{|c|}{ Do you know that rabies can be prevented by vaccinations? } \\
\hline No & Ref. & & & & & \\
\hline Yes & 0.168 & 0.384 & 0.191 & 0.662 & 1.183 & $0.565-2.575$ \\
\hline \multicolumn{7}{|c|}{ Whether there is an injury history of dog bites in the past year? } \\
\hline No & Ref. & & & & & \\
\hline Yes & 0.754 & 0.350 & 4.636 & 0.031 & 2.124 & $1.059-4.205$ \\
\hline \multicolumn{7}{|c|}{ Do you know that dogs should be vaccinated against rabies? } \\
\hline No & Ref. & & & & & \\
\hline Yes & 1.601 & 0.385 & 17.257 & 0.000 & 4.956 & $2.387-10.914$ \\
\hline \multicolumn{7}{|c|}{ Do you know where to vaccinate dogs against rabies? } \\
\hline No & Ref. & & & & & \\
\hline Yes & 0.519 & 0.301 & 2.973 & 0.085 & 1.681 & $0.934-3.051$ \\
\hline \multicolumn{7}{|c|}{ Do you know the local policy of dog vaccination against rabies? } \\
\hline Unknown & Ref. & & & & & \\
\hline Charges & 0.650 & 0.310 & 4.401 & 0.036 & 1.915 & $1.048-3.543$ \\
\hline Free & 1.191 & 0.473 & 6.342 & 0.012 & 3.290 & $1.285-8.296$ \\
\hline Constant & -3.736 & 0.783 & 22.768 & 0.000 & 0.024 & $0.005-0.107$ \\
\hline
\end{tabular}

Notes: The Ref. were used as control groups, such as male, primary school, and below. Rabies awareness rate of single knowledge point $=$ number of people answering correctly for single point /number of people answering this point; dogs are classified as immunized dog if it has been vaccinated once.

Abbreviations: $B=$ partial regression coefficient; S.E.=standard error; Wald=wald test; $\operatorname{Exp}(\mathrm{B})=$ odds ratio; $\mathrm{Cl}=$ confidence interval; Ref.= reference.

and people who knew the cost policy of dog vaccination may have access to acquire more knowledge about rabies. High understanding level about rabies prophylaxis knowledge and policy might drive people to vaccinate their dogs (5). In addition, local policies providing free canine rabies vaccines has reduced the economic burden on dog owners and further increased their willingness to vaccinate their dogs against rabies. This finding indicated that free mass vaccination program may help encourage dog owners in rural areas to have their dogs vaccinated.
In this study, among the dog owners who failed to vaccinate their dogs, $44.6 \%$ thought vaccinating dogs too troublesome and $31.5 \%$ did not know where to vaccinate dogs. Similarly, some previous studies also suggested other factors such as a limited number of vaccinating sites and veterinarians, long distance to the sites and veterinary clinic, and feeling difficulty confining the dogs for vaccination would prevent many dog owners from accessing rabies vaccinations (6-7). Therefore, supporting conditions for relevant policies, such as veterinary systems and a free policy, are also 
important factors affecting dog vaccination against rabies. It is suggested to establish more rural vaccination sites, increase the number of mobile vaccination sites, even consider door-to-door vaccinations to raise the accessibility of dog vaccination service in rural areas, improve treatment and subsidies of veterinarians, increase the number of veterinarians in rural areas, increase the vaccine types provided by the free policy, and strengthen awareness campaign for dog rabies immunization strategies and measures.

The results of this study suggested that $23.7 \%$ of all households owned dogs in rural areas of Guangxi Zhuang Autonomous Region, higher than $18.0 \%$ of a rural district in Beijing (8) and higher than urban areas in Guangxi Zhuang Autonomous Region of China (9). This is related to the reason of keeping dogs for house guarding (10). This research also found that only about $19.1 \%$ of dog-owning households reported having their dogs vaccinated, much lower than the minimum requirement to achieve interruptions in dog-mediated rabies spread (1) and also lower than that in economically developed regions, such as $85.0 \%-100.0 \%$ in Shanghai (10), 80.0\% in Beijing (11), and above $70 \%$ in the Pearl River Delta region in Guangdong Province (4). The findings illustrated that there will still be much room for improving rabies control when progress is achieved in the endemic area (12). This may also be due to a lack of an appropriate incentive system for veterinarians as insufficients veterinarians are at the grassroots level, which when coupled with the limited free vaccination policy coverage, may contribute to much lower vaccination rates in Guangxi Zhuang Autonomous Region when compared to megacities or more economically developed regions. The other reasons may be related to different measuring methods of coverage rate: some studies only include the registered dogs, while others also involve the unregistered dogs using a household survey. Veterinarians are only responsible to administer vaccines to registered $\operatorname{dogs}(11)$, but dogs in rural China are seldom registered and leashed, which are difficult to catch and inject with inactivated vaccines (13). Therefore, sub-par dog registration management in PLADs with poor economic development is also one of the reasons for the low vaccination coverage (13).

In conclusion, it is recommended to scale up free and more accessible mass dog vaccination campaign to reduce the rabies risk and even achieve "zero by 2030 " in rural areas of China, as well as conduct an awareness campaign. The revised edition of China National Animal Epidemic Prevention Law endorsed in March
2021 required dog owners to vaccinate their dogs against rabies (14), which will promote China towards the elimination of dog-mediated rabies.

This study was subject to some limitations. The dog immunization status was reported by dog owners, and interviewers neither checked the vaccination certificate nor collected data on the number of dogs owned, and the number of dogs vaccinated in each household. Therefore, the reported rate may have some discrepancy with actual cases. The ratios of captive and free roaming dogs and of once immunized dogs and annually immunized dogs are also unclear. Additionally, this study only considered the influence of $\operatorname{dog}$ owners on dog vaccination against rabies and did not include the factors associated with the service providers, such as veterinarians, and thus follow-up requiring further qualitative research should be conducted to provide more details to form a better vaccination program.

Conflicts of interest: No conflicts of interest.

Acknowledgements: Animals Asia and university student volunteers.

\section{doi: $10.46234 / \mathrm{ccdcw} 2021.218$}

\# Corresponding authors: Yanping Zhang, zhangyp@chinacdc.cn; Xianyan Tang, tangxianyan0746@163.com.

\footnotetext{
${ }^{1}$ School of Public Health, Guangxi Medical University, Nanning, Guangxi Zhuang Autonomous Region, China; ${ }^{2}$ Division of Infectious Disease, Key Laboratory of Surveillance and Early Warning on Infectious Disease, Chinese Center for Disease Control and Prevention, Beijing, China; ${ }^{3}$ Animals Asia, Chengdu, Sichuan, China.

\& Joint first authors.
}

Submitted: September 26, 2021; Accepted: October 08, 2021

\section{REFERENCES}

1. World Health Organization. Zero by 30: the global strategic plan to end human deaths from dog-mediated rabies by 2030. https://www. who.int/publications/i/item/9789241513838. [2021-8-5].

2. Tao XY, Liu SQ, Zhu WY, Rayner S. Rabies surveillance and control in China over the last twenty years. Biosaf Health 2021;3(3):142 - 7. http: //dx.doi.org/10.1016/j.bsheal.2020.11.004.

3. Department of Agriculture. National animal rabies prevention and control Plan (2017-2020). http://www.moa.gov.cn/nybgb/2017/dlq/ 201712/t20171231_6133713.htm. [2020-8-5]. (In Chinese).

4. Chen QL, Ma XY, Rainey JJ, Li Y, Mu D, Tao XY, et al. Findings from the initial Stepwise Approach to Rabies Elimination (SARE) assessment in China, 2019. PLoS Negl Trop Dis 2021;15(3):e0009274. http://dx. doi.org/10.1371/journal.pntd.0009274.

5. Li DD, Liu QY, Chen F, Jiang QQ, Wang TT, Yin XX, et al. Knowledge, attitudes, and practices regarding rabies and its prevention and control among bite victims by suspected rabid animals in China. One Health 2021;13:100264. http://dx.doi.org/10.1016/j.onehlt.2021. 100264.

6. Fenelon N, Dely P, Katz MA, Schaad ND, Dismer A, Moran D, et al. Knowledge, attitudes and practices regarding rabies risk in community members and healthcare professionals: Pétionville, Haiti, 2013. 
Epidemiol Infect 2017;145(8):1624 - 34. http://dx.doi.org/10.1017/ S0950268816003125.

7. Savadogo M, Soré AF, Dahourou LD, Ossebi W, Combari AHB, Bada Alambedji R, et al. Assessing factors associated with owner's individual decision to vaccinate their dogs against rabies: a house-to-house survey in Ouagadougou, Burkina Faso. Vet World 2021;14(4):1014 - 9. http:/ /dx.doi.org/10.14202/vetworld.2021.1014-1019.

8. Zhou B, Cao DQ, Fu HY, Peng SB, Shi WJ, Liu Y. An investigation of current pet keeping status of permanent residents in Mentougou district, Beijing, China and the influencing factors. Chin J Vector Biol Control 2020;31(2):227 - 30. http://dx.doi.org/10. 11853 j.j.issn.1003.8280.2020.02.023. (In Chinese).

9. Chen FF, Lu QZ, Zou LB, Gan HX, Wen LX, Hu LP, et al. Epidemiological analysis of rabies in Guangxi from 2008 to 2010. Urban Const Theory Res: Electron Ed 2011;(23). https://d. wanfangdata.com.cn/periodical/ChlQZXJpb2RpY2FsQ0hJTmV3UzIw MjEwOTA5EhJjc2pzbGx5ajIwMTEyMzMwMTgaCDk1cnhpN3d4. (In Chinese)

10. Wu XJ, Yu VY, Huang Z, Lu J, Tang WH, Shen SF, et al. Estimation of the rural dog population within a Mega-City: an example in Jiading District, Shanghai. Front Vet Sci 2021;8:630180. http://dx.doi.org/ 10.3389/fvets.2021.630180

11. Zhang JY, Zhang B, Zhang SF, Zhang F, Li N, Liu Y, et al. Dogtransmitted Rabies in Beijing, China. Biomed Environ Sci 2017;30(7): 526 - 9. http://dx.doi.org/10.3967/bes2017.069.

12. Wei XK, Xiong Y, Li XN, Zheng M, Pan Y, He XX, et al. Vaccination demonstration zone successfully controls rabies in Guangxi Province, China. BMC Infect Dis 2018;18(1):386. http://dx.doi.org/10.1186/ s12879-018-3301-8.

13. Miao FM, Li N, Yang JJ, Chen T, Liu Y, Zhang SF, et al. Neglected challenges in the control of animal rabies in China. One Health 2021;12:100212. http://dx.doi.org/10.1016/j.onehlt.2021. 100212.

14. The National People's Congress of the People's Republic of China. Animal epidemic prevention law of the People's Republic of China. http://www.npc.gov.cn/npc/c30834/202101/bcedb2c057984cb680f8cc 54529c0940.shtml. [2021-1-22]. (In Chinese). 